\title{
Using the Text
}

The following is offered only as helpful suggestions for instructors and students who will be using this text. There are many ways to use this book, depending on the instructor's creative pedagogy.

\section{PACE OF STUDY}

This text is designed for a course that covers about one lesson a week for two fifteen-week semesters. Although there are twenty-seven lessons in all, we have found that they more than suffice for two semesters. In our experience with the text, only twelve or thirteen lessons are covered each semester because holidays or impromptu classroom activities such as skits, simple debates, or speeches intervene and because some lessons require more than a week of coverage. If the instructor wishes to rearrange the order of the lessons or skip a lesson, there should be little difficulty in doing so because each lesson is a self-contained unit.

\section{INTRODUCING EACH LESSON}

Most lessons begin with a short introductory narrative to set the stage or give background information for a dialogue that follows. This material is followed by the vocabulary needed to comprehend the content of the lesson. We have tried two ways of presenting the vocabulary. Each has worked well. On one hand, the instructor may introduce the vocabulary first, carefully going over the new expressions. This may include even the vocabulary activities in part $\mathrm{C}$ of the exercises. After learning 
the words, students find the content of the lesson easy to understand and interesting. Some instructors may want to give a vocabulary quiz immediately before getting into the lesson. On the other hand, the instructor may read through the lesson with students for the first hour to introduce the content and to provide the meaning of unfamiliar words and any necessary cultural information. Students are expected to internalize the vocabulary by the next day (when they take a short vocabulary quiz).

\section{ORAL PRACTICE}

The dialogue portion of a lesson is read and practiced by students in pairs (or in groups, according to the number of actors in the dialogue). They do not have to follow the script verbatim as long as they use the newly introduced words, phrases, and/or patterns. In part C of the lesson exercises, students are encouraged to say things in various ways, using as many new and related words as possible. Students may also be assigned to record their dictation of a short passage, the telling of an anecdote, or the reading of an essay, drawing from the suggested conversation topics in part $\mathrm{D}$ of the lesson exercises. The audiotapes are reviewed for pronunciation and for grammar and content errors and are returned to students for their review and correction. Students may also present stories or skits they have written or hold discussions or debates on a topic.

\section{LISTENING COMPREHENSION}

In addition to what is given in sections $\mathrm{A}$ and $\mathrm{B}$ of the exercises and on the accompanying audiotapes (which are available through the University of California at Berkeley Language Laboratory: LL-DUP@socrates. berkeley.edu or the University of Michigan Language Laboratory Resource Center: flacs@umich.edu), each student could be assigned to make a true-or-false statement based on the reading and to ask the rest of the class to respond. The instructor may also choose to prepare and read a short script or a narration (per the samples in the workbook) based on the content and vocabulary of the lesson; students listen and are checked for their comprehension. Group discussions, oral presentations, role- 
playing, and skits also provide students opportunities to practice their listening skills as well as their speaking skills.

\section{WRITING EXERCISE}

Each lesson has a short writing assignment in the homework packet. It can be a summary of the lesson, an opinion on some topic, a simple description, or a letter incorporating the new words, idioms, and structural patterns from the lesson. Also, students should keep a record of any frequent errors they make in spelling, usage, or grammar on tests, homework, and writing assignments so that they can correct and review any problem areas throughout the semester.

\section{USING VIDEOS INTRODUCING KOREAN CULTURE}

Since the text is about culture, places, and current issues, instructors may be interested in the many informative and relevant videos that are available through the Office of Information at Korean consulates or even at local Korean video shops. Some segments of Korean television news programs, documentaries, or soap operas may be useful, with a careful selection of content and a presentation that is appropriate for the level of the class.

\section{SINO-KOREAN GHARACTERS}

For today's students of Korean, we have delayed introducing the SinoKorean (Chinese) characters in depth until the advanced level. However, for students who are interested in taking up the additional task, we provide about 100 basic Sino-Korean characters in the workbook appendix for optional work.

\section{REVIEW AND TESTS}

A written test every other week covering two chapters on the fifth day of the second week works nicely for the intermediate level, thus leaving the 
fifth day of the first week for presentations, skits, videos, or other related activities. Some instructors may prefer a weekly test after each chapter. A midterm vocabulary review quiz is also useful for reinforcing students' acquisition of the new words.

These points are merely guides to the users of this book and leave ample room for instructors to alter, improve, and be creative with the lessons. 